
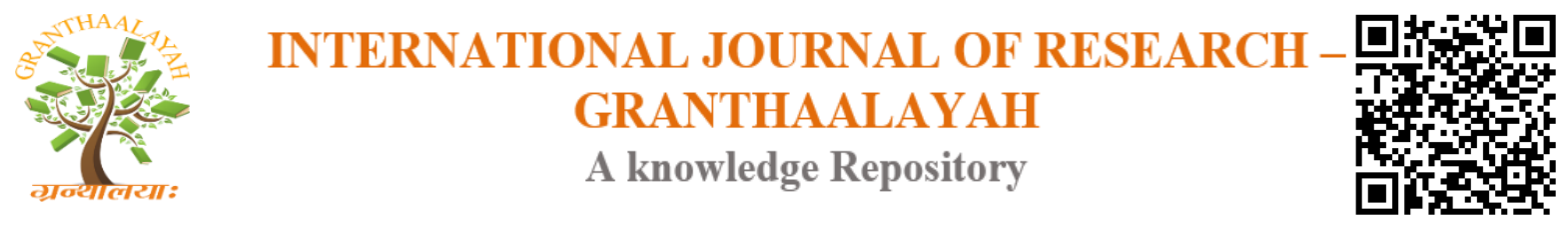

Social

\title{
EVALUATION OF THE SOCIAL BEHAVIOR OF ADOLESCENT STUDENTS AT SCHOOL
}

\author{
Lemonia Darginidou *1 \\ ${ }^{* 1}$ Math, MeD, PhD, Department of Physical Education \& Sports Sciences, Democritus \\ University of Thrace, Greece
}

\begin{abstract}
The ability of adolescents to participate in the learning process at school requires a proper social behavior and social abilities such as cooperating skills, empathy and suspension of quick temperedness and disruptiveness. The aim of this research is to evaluate the social behavior of male and female students at school and study the influence of gender on factors of social behavior. The sample of the research consisted of 181 male and female students aged 12-13. The questionnaire used was the School Social Behavior Scale (SSBS), followed by a credibility analysis. T-tests were carried out, which confirmed the statistically important difference between the factor "quick temperedness" and the factor "gender". The results of the research show that both male and female students present a positive social behavior, with the male students being more quick-tempered.
\end{abstract}

Keywords: Male/Female Students; Social Behavior.

Cite This Article: Lemonia Darginidou. (2019). "EVALUATION OF THE SOCIAL BEHAVIOR OF ADOLESCENT STUDENTS AT SCHOOL." International Journal of Research - Granthaalayah, 7(1), 260-268. https://doi.org/10.29121/granthaalayah.v7.i1.2019.1053.

\section{Introduction}

The latest orientations of education tend to develop attitudes and social skills, which influence the objectives of all school subjects.

The ability of adolescents to participate in the learning process at school requires a proper social behavior and social abilities such as cooperating skills, empathy and restrain of quick temperedness and disruptiveness.

Social behavior, during the learning process, can be influenced by the students' ability to handle their emotions and anxiety, while an effective social disposition can be related to the students' level of understanding rules and situations as well as their ability to regulate intense emotions such as anger and recover. 
An important factor for the development of the personality of children and adolescents is their ability to maintain social relationships, which are also connected with their success at school (Kennedy, 1988). Consequently, adolescents must be equipped with social skills, which are indispensable for initiating and maintaining social relationships with the members of their family, their fellow students, their teachers and other parts of society. Anti-social behavior at this age is related to future dangerous and undesirable behaviors such as the use of alcohol or drags (Caspi, Elder \& Bem, 1987). School could be an ideal environment for students to develop social skills which, as it has been supported, are connected to learning experiences (Wentzel, 1991).

The most important mission of school is the development and improvement of students' individual abilities and their social coordination (Hargreaves, 1999). In addition, according to research data and supporters of the developmental theory such as Binet, Dewey, Piaget, Freud as well as other modern followers of the developmental and social psychology, one could assume that teaching at school should not just focus on the cognitive approach of subjects but also on shaping behaviors and offering experiences which integrate students' personalities (Kougioumtzakis, 1997). Therefore, school is the proper environment for students to develop social skills (Kennedy,1988) so that, in their adult life, they can develop a positive social behavior (Sharpe, Brown, \& Crider, 1995).

\subsection{Socialization}

A person is considered successfully socialized, when he/she can create and handle social relationships, does not inflict damage on others and can be a significant member of a group, that could be his/her family, school or society in general (Shaffer, 2008).

Socialization is part of the children and adolescents' social development, in the frame of which young people acquire values, models and knowledge of the society in which the live and belong. Parents, teachers and adults are the socialization agents who transmit socially acceptable behaviors to the new generation of a certain cultural group (Ogbu, 1981; Triandis, 1989). Teachers, as socialization agents, influence young people's development (Ogbu, 1981) and since they are less emotionally involved than parents, they can be more objective (Shaffer, 2008). Thus, they are considered to complete the children and adolescents' socialization.

\subsection{Modes of Social Behavior}

Although social behavior is hard to define, it could be described as a person's ability to realize and maintain a positive sociability and relationships with peers, organizing his/her own personal potentials (Boyom \& Parke,1995; Ladd, 1999). It comprises the communication and personal activity developed by people, when they are with other people.

People's activity leads to social results and consequences, which differ according to weather their behavior is positive or negative (Merrell, Sanders \& Popinga, 1993). Concerning adolescents, positive social behavior is the positive way in which they interact with their peers. Furthermore, positive social behavior is the behavior which increases the possibility for reward and social enhancement and reduces the possibility for unpleasant social consequences towards its agent. 
Negative social behavior or anti-social behavior is the negative way in which adolescents interact with their peers, which leads to negative social results and consequences for its recepients (Gresham, 1986; Gresham, \& Reschly, 1987).

There are researchers supporting that model imitation, self-enhancement, self-guidance and other principles of social and socio-cognitive learning can be supportive of teaching positive social behavior to adolescents (Hops, 1983; Koliadis, 2005). Socially accepted behavior constitutes a social skill which is acknowledged by family, school and adolescent peers. In addition, it leads to popularity, acceptance by the group and favorable judgment towards its applicant (Asher \& Hymel, 1981). A person who acquires social skills is characterized by social support and the possibility to develop skills, through interaction and qualitative interpersonal relationships (Mc Combs, 1991). Social support is important to adolescents and can be provided by parents, teachers, peers and people who are considered important for young people (Harter, 1996).

\subsection{Factors of Positive Social Behavior}

Two dimensions or factors of positive social behavior are cooperating skills and empathy. They represent a person's ability to reveal and communicate positive emotions effectively.

Cooperating skills constitute a positive social behavior. They are characterized by an exchange and mutuality of thoughts, emotions and actions and they are related to the interactions among the members of a group, in order to carry out a certain goal or project (Johnson \& Johnson, 1989b). In addition, since their role has been found to be particularly significant for the prediction of people's psychological well being (Junttila, Vauras \& Laakkonen, 2007), they should be developed and taught to children and adolescents (McDevitt \& Ormrod, 2002; Webb \& Farivar, 1994).

Empathy is also an indication of positive social behavior. It is the ability to participate in someone else's psychological situation, to understand and identify with another person's experiences and respond with discretion and sensitivity (Cliffordson, 2002). Empathy is defined by a someone's sensitivity towards the others, while cooperating skills are required in order that a person function in various situations, such as collaborative learning, with common objectives (Englund, Levy, Hyson \& Sroufe, 2000).

\subsection{Factors of Anti-Social Behavior}

Anti-social behavior has negative social consequences.

Anti-social behavior can be manifested through quick temperedness and disruptiveness. Quick temperedness is a behavior which is expressed with nervous agitation, manifestations of anger and a person's inability to resist temptations and negative stimulations and it occurs without any conscious intention to harass the others (Farmer, 2000). Quick tempered is a person who has difficulty programming and waiting for a goal to be achieved and cannot suspend obvious mechanical movements, in order to respond to the requirements of occasional situations (Bear \& Nietzel, 1991). 
Disruptiveness, which can be detected on a verbal or kinetic level, is a behavior aiming at harassing and consciously disrupting the smooth climate within a group (Farmer, 2000). Quick temperedness is an obvious factor of dangerous anti-social behavior, while disruptiveness is a behavior which addresses to others, with the intention to harm or harass them.

\section{Materials and Methods}

\subsection{Aim}

The aim of this research is to evaluate the social behavior of male and female students at school and study the influence of gender on social behavior factors.

\subsection{Research Hypotheses}

Students present a positive social behavior.

Gender can be a differentiation factor of social behavior.

\subsection{Sample}

The sample of the research included 181 male and female students aged 12-13. Table 1 presents the composition of the sample, regarding gender.

Table 1: Composition of the sample

\begin{tabular}{|c|c|c|}
\hline Sex & $\mathbf{N}$ & $\mathbf{\%}$ \\
\hline Boy & 83 & 45,86 \\
\hline Girls & 98 & 54,14 \\
\hline Total & 181 & 100,00 \\
\hline
\end{tabular}

\subsection{Research Tools}

The instrument used to measure the male/female students' social behavior was the Social Behavior Scale (SSBS) (Merrell, 1993), adjusted for the Greek population (Magotsiou, Goudas \& Hasandra, 2006). The validity and credibility of the questionnaire has been confirmed in other researches in Greece, where it was used successfully (Goudas \& Magotsiou, 2009; Katsanos, Kouvelas, Samara $\&$ Hasandra, 2008). The questionnaire consists of 23 questions, grouped in four factors of social behavior:

- The first factor is called "Cooperating skills" and includes 5 questions (e.g. "I work as a team with my fellow students"). It examines male and female students' ability to interact effectively, when they belong in a group.

- The second factor is called "Empathy" and includes 6 questions (e.g. "I am interested in other people's emotions"). It examines male and female students' interest in other people's emotions and the way they respond.

- The third factor is called "Disruptiveness" and includes 6 questions (e.g. "I cause agitation in class"). It examines a student's conscious cause of disruptiveness, in order to disturb the smooth climate in a group. 
- The fourth factor is called "Quick temperedness" and includes 6 questions (e.g. "I often get annoyed and angry"). It examines the anger and nervous agitation of male and female students in class, either intentionally or not. To fill in the questionnaire, all students have to evaluate their social behavior themselves, on a 5 degree Likert scale (from 1=I totally disagree, to $5=$ I totally agree).

\subsection{Statistical Analysis}

Initially, there was a meeting between the researcher and the students during their free time, in order that the students get informed about the content and the aims of the research. Next, the participants filled in the questionnaire of the research within 15-20 minutes and they handed it to the researcher. Their participation was voluntary.

During the statistical analysis of the data, the main variables of the research were defined by the four factors of social behavior (cooperating skills, empathy, disruptiveness and quick temperedness), which were encoded in order to be inserted in the statistical program SPSS v.18. There were descriptive methods (means, typical deviations and percentages), credibility analyses to estimate Cronbach's $\alpha$ and t-tests for independent samples.

\section{Results and Discussions}

\subsection{Credibility Analysis}

The credibility analysis results showed that all social behavior factors have a very good internal cohesion, since Cronbach's $\alpha$ values were bigger than 0.88 . Table 2 presents the means, typical deviations and credibility analyses of the social behavior factors.

Table 2: Means, typical deviations and credibility analyses of the social behavior factors of male and female students at school

\begin{tabular}{|l|c|c|c|}
\hline \multicolumn{1}{|c|}{ Subscales } & M & S.D & a Cronbach's \\
\hline Cooperating Skills & 3.95 & 0.48 & 0.95 \\
\hline Empathy & 3.74 & 0.52 & 0.98 \\
\hline Disruptiveness & 1.50 & 0.36 & 0.89 \\
\hline Quick temperedness & 1.43 & 0.57 & 0.88 \\
\hline
\end{tabular}

Checking the existence of statistically significant differences concerning gender

To check the existence of statistically significant differences of social behavior (cooperating skills, empathy, disruptiveness and quick temperedness) concerning gender there were t-tests for independent samples. Table 3 presents the students' examined factors of social behavior, the means, the typical deviations and the results of the t-test statistical analyses of the social behavior factors concerning gender. 
Table 3: Means, typical deviations and results of the t-test statistical analyses of the social behavior factors concerning gender

\begin{tabular}{|c|c|c|c|c|}
\hline Subscales & Sex & M & S.D & t \\
\hline Cooperating Skills & Boy & 3.91 & 0.51 & $\mathrm{t}(179)=0.935, \mathrm{p}>0.05$ \\
\cline { 2 - 4 } & Girl & 3.98 & 0.44 & \\
\hline \multirow{2}{*}{ Empathy } & Boy & 3.68 & 0.61 & \multirow{t}{*}{$\mathrm{t}(179)=1.541, \mathrm{p}>0.05$} \\
\hline & Girl & 3.80 & 0.43 & \\
\hline Disruptiveness & Boy & 1.51 & 0.40 & $\mathrm{t}(179)=0.279, \mathrm{p}>0.05$ \\
\cline { 2 - 4 } & Girl & 1.50 & 0.31 & \\
\hline Quick temperedness & Boy & 1.52 & 0.64 & \multirow{2}{*}{$\mathrm{t}(179)=2.034, \mathrm{p}<0.05$} \\
\cline { 2 - 4 } & Girl & 1.35 & 0.50 & \\
\hline
\end{tabular}

The application of t-tests for independent samples gave the following results:

- There was a statistically significant difference between the factor "Quick temperedness" and the factor "gender" $(\mathrm{t}(179)=2.034, \mathrm{p}<0.05)$. Observing the means (Table 3$)$ it can be confirmed that male students $(\mathrm{M}=1.52$, S.D. $=0.64)$ present higher means in the factor "Quick temperedness" than female students (M=1.35, S.D. $=0.50)$.

- There were no statistically significant differences among the factors "Cooperating skills" $(\mathrm{t}(179)=0.935, \quad \mathrm{p}=>0.05)$, "Empathy", $\quad(\mathrm{t}(179)=1.541, \quad \mathrm{p}=>0.05)$, "Disruptiveness" $(\mathrm{t}(179)=0.279, \mathrm{p}>0.05)$ and the factor "Gender".

\section{Conclusions and Recommendations}

The aim of this research was to evaluate the social behavior of male and female students at school and study the influence of gender on factors of social behavior, concerning male and female students aged 12-13.

All students evaluated their social behavior themselves and the results showed that both male and female students have a positive social behavior. The means of the social behavior factors "cooperating skills" and "empathy" were high on the 5 degree scale of the questionnaire.

It is important that there exist cooperating skills among male and female students, because their development is a characteristic of socialization, which is the aim of school (Hargreaves, 1999). Through discussing and solving problems at school, male and female students develop relationships of mutual help, trust, cooperation and positive interdependence, while they improve their interpersonal relationships and become social persons.

There was no differentiation between the two factors of positive behavior i.e. "cooperating skills" and "empathy". Thus, both boys and girls present a positive social behavior and they acquire social skills which they use properly in their interpersonal relationships at school.

Furthermore, the results of the research show that neither male nor female students presented a negative social behavior. The means of the negative factors of social behavior i.e. "disruptiveness" and "quick temperedness" were low on the 5 degree scale of the questionnaire. 
Gender caused a differentiation in the factor "quick temperedness", with the boys being more quick-tempered than girls, since their means were higher than those of girls. Other researchers have revealed that pre-school boys and girls present different levels of social skills and behavior (Deater-Deckard, Dodge, Bates \& Pettit, 1998; Steinberg \& Dodge, 1983), with the girls usually presenting a better social behavior than boys (Elliott, Barnard \& Gresham, 1989; Kochanska, 1997) and the boys being more susceptible to presenting negative forms of behavior (Hammarberg \& Hagekull, 2006).

While molding their image, male and female adolescents are faced with emotional tension, anxiety and internal conflicts which are expressed with insecurity, uncertainty and insufficient ability (Makri-Mpotsari, 2008). These phenomena, which are normal during adolescence, were expressed during the research as quick temperedness, which was more intense for boys than for girls. After all, adolescence is a period of increased instability and emotional conflict, as mentioned by Rousseau, while Hall describes it as a period of anxiety and tempest.

\section{Acknowledgements}

The researchers propose further examination that will include a larger sample of adolescent students.

\section{References}

[1] Asher, S. R. \& Hymel, S. (1981). Children's social competence in peer relations: sociometric and behavioral assessments. In J. D. Wine \& M.D. Smye (Eds). Social competence. New York, Guilford.

[2] Bear, R. A. \& Nietzel, M. T. (1991). Cognitive and behavioral treatment of impulsivity in children: A meta-analytic review of the outcome literature. Journal of Clinical Child Psychology, 20(4), 400412.

[3] Boyom, L.A. \& Parke, R. D. (1995). The role of family emotional expressiveness in the development of children's social competence. Journal of Marriage \& Family, 57(3), 593-618.

[4] Caspi, A., Elder, G. H., \& Bem, D.J. (1987). Moving against the world: Life-course patterns of explosive children. Developmental Psychology, 23, 308-313.

[5] Cliffordson, C. (2002). The hierarchical structure of empathy: Dimensional organization and relations to social functioning. Scandinavian Journal of Psychology, 43, 49-59.

[6] Deater-Deckard, K., Dodge, K. A., Bates, J. E., \& Pettit, G. S. (1998). Multiple risk factors in the development of externalizing behavior problems: Group and individual differences. Development and Psychopathology, 10 (3), $469-493$.

[7] Elliott, S. N., Barnard, J. \& Gresham, F. M. (1989). Preschoolers' social behavior: Teachers' and parents' assessments. Journal of Psycho educational Assessment, 7(3), 223-234.

[8] Englund, M.M., Levy, A.K., Hyson, D.M. \& Sroufe, L.A. (2000). Adolescent social competence: Effectiveness in a group setting. Child Development, 71(4), 1049-1060.

[9] Farmer, T. W. (2000). The social dynamics of aggressive and disruptive behavior in school. Implications for behavior consultation. Journal of Educational and Psychological Consultation, 11, 299-321.

[10] Goudas, M. \& Magotsiou, E. (2009). The effects of a cooperative physical education program on Students' social skills. Journal of Applied Sport Psychology, 21, 356-364.

[11] Gresham, F. M. (1986). Conceptual and Definitional issues in the Assessment of Children's Social Skills: Implications for Classifications and Training. Journal of Clinical Child Psychology, 15(1), 3-15. 
[12] Gresham, F.M. \& Reschly, D. J. (1987). Dimensions of Social Competence: Method Factors in the Assessment of Adaptive Behavior, Social Skills and Peer Acceptance. Journal of School Psychology, 25, 108-117.http://dx.doi.org/10.1016/0022-4405(87)90038-0.

[13] Hammarber, A. \& Hagekull, B. (2006). Changes in externalizing and internalizing behaviors over a school-year: Differences between 6-year-old boys and girls. Infant and Child Development, 15 (2), 123-137.

[14] Hargreaves, A. (1999). Teaching in the Knowledge Society: Education in the Age of Insecurity. Teachers College Press.

[15] Harter, S. (1996). Historical roots of contemporary issues involving self-concept. In: B.A. Bracken (Ed.), Handbook of self-concept, New York, NY, John Wiley \& Sons, Inc

[16] Hops, H. (1983). Children's social competence and skill: Current research practices and future directions. Behavior Therapy, 14(1) 3-18.

[17] Johnson, D.W. \& Johnson, R. (1989b). Leading the cooperative school. Edina, MN: Interaction Book Company.

[18] Junttila, N., Vauras, M. \& Laakkonen, E. (2007). The role of parenting self-efficacy in children's social and academic behavior. European Journal of Psychology of Education, 22(1), 41-61.

[19] Katsanos, A., Kouvelas, B., Samara, E. \& Chasandra, M. (2008). Relations of social behavior at school and fair play behaviors in physical education (in Greek). In Proceeding of 16th International congress of physical education and sports. Komotini: Democritus University of Thrace.

[20] Kennedy, J. H. (1988). Issues in the identification of socially incompetent children. School Psychology Review, 17, 276-288.

[21] Kochanska, G. (1997). Multiple pathways to conscience for children with different temperaments: From toddlerhood to age 5. Developmental Psychology, 33,228 - 240.

[22] Koliadis, E. (2005). Learning theories and educational act. Vol. A. Behavioral theories (in Greek). Athens: Self-publishing.

[23] Kougioumtzakis, G. (1997) Developmental psychology. Past, present and future (in Greek). University press of Grete.

[24] Ladd, G. W. (1999). Peer relationships and social competence during early and middle childhood. Annual Review of Psychology, 50, 333-359.

[25] McCombs, B. L. (1991). Motivation and lifelong learning. Educational Psychologist, 26(2), 117127.

[26] Magotsiou, E., Goudas, M. \& Hasandra, M. (2006). Validity and reliability of the Greek version of the Multisource Assessment of Social competence Scale. Perceptual and Motor Skills, 103, 667675.

[27] Makri-Mpotsari, E. (2008). Modern problems of teenagers (in Greek). Inhttps://repository.edulll.gr/edulll/bitstream/10795/1090/4/1090_02_oaed_summary_enotita03b_ v01.pdf

[28] McDevitt, T.M. \& Ormrod, J.E. (2002). Child development and education. Upper Saddle River, NJ: Merrill Prentice Hall.

[29] Merrell, K. W. (1993). School social behavior scales. Iowa City: Assessment- Intervention Resources, In Magotsiou, E. (2007). Creation, implementation and evaluation of a social skills program in the physical education course (in Greek). Unpublished Doctoral Thesis. Department of Physical Education and Sport Science, University of Thessaly, Trikala.

[30] Merrell, K.W., Sanders, D.E. \& Popinga, M.R. (1993). Teacher Ratings of Student Social Behavior as a Predictor of Special Education Status: Discriminant Validity of the School Social Behavior Scales. Journal of Psycho educational Assessment, 11, 220-231.

[31] Ogbu, J. (1981). Origins of human competences. A cultural ecological perspective. Child development, 52,413-429.

[32] Shaffer, D.R. (2008). Evolutionary psychology. Childhood and adolescence (in Greek). Athens, Hellenic 
[33] Sharpe, T., Brown, M., \& Crider, K. (1995). The effects of a sportsmanship curriculum intervention on generalized positive social behavior of urban elementary school students. Journal of behavior analysis, 28(4), 401-416.

[34] Steinberg, M. S. \& Dodge, K. A. (1983). Attribution bias in aggressive adolescent boys and girls. Journal of Social \& Clinical Psychology, 1(4), 312 - 321.

[35] Triandis, H.C. (1989). Major cultural syndromes and emotions. In Kitayama, S. \& Markus, H.R. (ed). Emotion and culture, (pp 285-306). American psychological association.

[36] Webb, N. \& Farivar, S. (1994). Promoting helping behavior in cooperative small groups in middle school mathematics. American Educational Research Journal 31, 369-395.

[37] Wentzel, K. R. (1991). Social competence at school. Relation between social responsibility and academic achievement. Review of Educational Research, 61, 18-24.

*Corresponding author.

E-mail address: ldargini@ phyed.duth.gr 